\title{
Case report. Emfysemateuze pyelonefritis bij kinderen
}

\author{
Rens A. L. Jacobs · Piet R. H. Callewaert
}

Geaccepteerd op: 29 januari 2021 / Published online: 16 februari 2021

(C) The Author(s) 2021

Samenvatting In dit case report beschrijven wij het diagnose- en behandeltraject van een 12-jarige patiënt met een emfysemateuze pyelonefritis (EPN) ten gevolge van een pyelo-ureterale junctie stenose. Een EPN bij kinderen is uiterst zeldzaam. De exacte pathogenese van EPN is onbekend, maar het voorkomen lijkt geassocieerd te zijn met obstructie van de urinewegen, stenen of een gestoorde afweer. In tegenstelling tot bij de volwassen populatie met EPN lijkt diabetes mellitus bij kinderen geen risicofactor. Het klinisch beeld van EPN kan variëren van symptomen die passen bij een klassieke pyelonefritis tot een ernstige septische shock. Computertomografisch onderzoek vormt de beste diagnostische modaliteit. Behandeling bestaat uit spoedige resuscitatie van de septische patiënt in combinatie met drainage van de nier in geval van obstructie. De klinische uitkomst bij kinderen is over het algemeen goed.

Trefwoorden emfysemateuze pyelonefritis . kinderen · pyelo-ureterale junctie stenose

\section{Case report. Emphysematous pyelonephritis in children}

\begin{abstract}
In this case report we describe a 12 year old patient with an emphysematous pyelonephritis (EPN) due to an uretero-pelvic junction stenosis. An EPN in children is extremely rare. The pathogenesis is largely unknown but seems to be related to urinary tract obstruction, urinary stone disease or a decreased immunity. In contrast to the adult population with EPN diabetes mellitus doesn't seem to be a major risk fac-
\end{abstract}

drs. R. A. L. Jacobs · drs. P. R. H. Callewaert $(\bowtie)$

afdeling Urologie, Maastricht Universitair Medisch

Centrum, Maastricht, Nederland

piet.callewaert@mumc.nl tor in children. The clinical picture of EPN varies from symptoms of a classic pyelonephritis to a severe septic shock. Computer tomographic imaging forms the best diagnostic modality. Treatment consists of early resuscitation of the septic patient in combination with drainage of the kidney in case of obstruction. The clinical outcome in children is generally good.

Keywords emphysematous pyelonephritis . children · ureteropelvic junction stenosis

\section{Introductie}

Een emfysemateuze pyelonefritis (EPN) is een ernstige infectie van de nier die gepaard gaat met gasformatie in het pyelocalicieel systeem, het nierparenchym of in het perirenale weefsel. Dat EPN bij volwassenen voorkomt is bekend. Bij de pediatrische populatie daarentegen is EPN, met tot op heden acht gepubliceerde casus wereldwijd, een zeldzaam verschijnsel. In dit artikel bespreken wij een casus van EPN bij een 12jarige jongen.

\section{Casus}

Een 12-jarige patiënt met een blanco medische voorgeschiedenis presenteert zich op de Spoedeisende Hulp van ons academisch ziekenhuis. De patiënt klaagt over een sinds twee dagen bestaande continue, pijn in zijn rechter hemiabdomen en flank. Er is sprake van pollakisurie en troebele urine. Heteroanamnestisch is er sprake van piekende koorts tot $39^{\circ} \mathrm{C}$, lethargie en verwardheid. Er is geen voorgeschiedenis van mictieklachten, hematurie, nefro-urolithiase of urineweginfecties. Twee weken eerder zou er sprake zijn geweest van een cellulitis van de scrotale huid waarvoor een kortdurende antibiotische behandeling 
Figuur 1 Transversale en coronale afbeelding van de rechter nier waarbij het kelkbekkensysteem wordt afgelijnd door gasvorming. Ventraal in het pyelum wordt een lucht-vloeistofspiegel geobjectiveerd
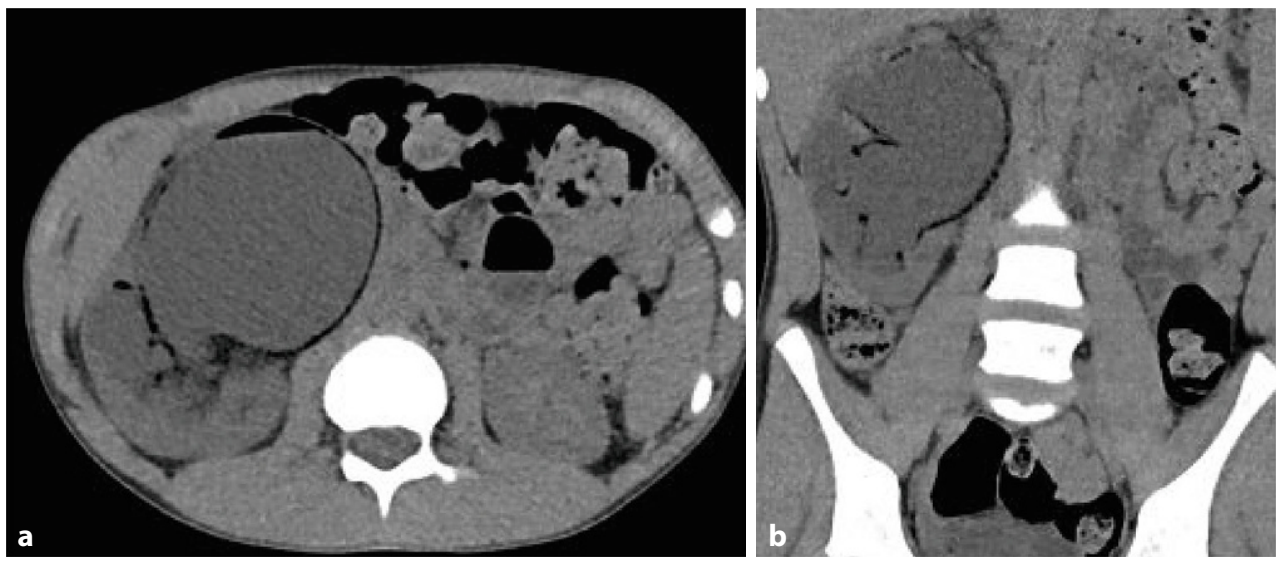

werd voorgeschreven. De overige tractusanamnese is niet bijdragend.

Het lichamelijk onderzoek toont een slanke niet acuut zieke jongeman met een bloeddruk van 99/59 $\mathrm{mmHg}$, een pols van 97 slagen per minuut en een temperatuur van $36,6^{\circ} \mathrm{C}$. Behoudens een duidelijke nierslagpijn rechts is het resterende lichamelijk onderzoek zonder afwijkingen. Laboratoriumonderzoek toont normale elektrolyten, een creatinine van $58 \mu \mathrm{mol} / \mathrm{l}$, een hemoglobine van $6,9 \mathrm{mmol} / \mathrm{l}$, leukocyten van $6,9 \times 10^{9} / \mathrm{l}$, trombocyten $144 \times 10^{9} / \mathrm{l}$, een C-reactive proteïne (CRP) van $53 \mathrm{mg} / \mathrm{l}$, een (niet-nuchtere) glucose van $7,4 \mathrm{mmol} / \mathrm{l}$ en een aPTT en PT van respectievelijk 28 en 12,5 seconden. Veneus bloedgas is normaal. Het urinesediment toont een significante pyurie met een positieve nitriet. Een Gram-kleuring toont Gram-negatieve staven. Echografisch onderzoek laat een graad 4-hydronefrose van de rechter nier zien met mobiel hyperechogeen materiaal in de kelken. De linker nier is normaal. De blaas is matig gevuld, maar vertoont een normale contour. Een aanvullend CT-abdomen zonder contrast bevestigt een forse hydronefrose rechts met een axiale pyelumdiameter van ruim $5 \mathrm{~cm}$. Er wordt een acute kalibersprong van het pyelum naar de proximale ureter gezien zonder duidelijk concrement. Bovendien wordt uitgebreide gasvorming tegen de wand van pyelum en calices gezien. Er bevindt zich een luchtvloeistofspiegel aan de ventrale zijde van het pyelum (fig. 1). De linker nier evenals het overige abdomen vertonen geen bijzonderheden.

De diagnose emfysemateuze pyelonefritis bij het vermoeden van een stenose van de pyelo-ureterale junctie (PUJ) wordt gesteld. Meteen wordt gestart met intraveneus vocht en breedspectrumantibiotica (amoxicilline/clavulaanzuur met gentamicine). Kort daarna wordt bij de patiënt aan de rechterzijde een 8 French nefrostomie geplaatst. Er loopt donker troebel vocht af, dat voor aanvullend bacteriologisch onderzoek naar het laboratorium wordt verstuurd.

De urinekweken tonen een Escherichia coli. Bloedkweken zijn negatief. De patiënt vertoont na drainage een vlot klinisch herstel en wordt op geleide van de kweekuitslagen antibiotisch uitbehandeld gedurende 14 dagen. Een DMSA-scan toont een heterogene perfusie van de rechter nier met mogelijk wat cortexverlies in de boven- en interpolaire regio, passend bij een status na doorgemaakte pyelonefritis. De relatieve bijdrage aan de globale nierfunctie is $55 \%$ voor de rechter nier. Een antegraad pyelogram bevestigt een fors uitgezet verzamelsysteem rechts zonder dat er afloop wordt gezien richting de proximale ureter (fig. 2a). De uroflowmetrie is met een $\mathrm{Q}_{\max }$ van $28 \mathrm{ml}$ per seconde bij een volume van $135 \mathrm{ml}$ niet afwijkend. Een significant residu na mictie wordt uitgesloten.

Vier weken na opname wordt een robotgeassisteerde pyelumplastiek aan de rechterzijde verricht. Preoperatief wordt een cystoscopie met retrograad pyelogram vervaardigd, waarbij een normale blaas met twee orthotope ostia wordt gezien. De rechter ureter heeft een normaal anatomisch beloop en het pyelocalicieel systeem is slank en laat zich goed vullen bij afgeklemde nefrostomie in situ (fig. 2b). Peroperatief worden grote overkruisende onderpoolsvaten geïdentificeerd (fig. 3). Na antegrade vulling van het pyelocalicieel systeem via de nefrostomie bestaat de indruk dat deze overkruisende vaten verantwoordelijk zijn voor een relatieve ureterobstructie. De PUJ wordt vervolgens ventraal van de overkruisende onderpoolsvaten gereconstrueerd. Endoluminale inspectie van de PUJ toont geen intrinsieke junctiestenose. De nefrostomie blijft postoperatief in situ en er wordt geen JJ-stent geplaatst. De patiënt kan drie dagen postoperatief het ziekenhuis in goede conditie verlaten.

\section{Discussie}

Een emfysemateuze pyelonefritis (EPN) is een infectie van de nier die gepaard gaat met gasformatie in het pyelocalicieel systeem, het nierparenchym of in het perirenale weefsel. Sommige auteurs suggereren echter dat de term EPN alleen mag worden gebruikt wanneer er sprake is van gasformatie in het parenchym of in het perirenale weefsel. Bij alleen gasformatie in het verzamelsysteem dient men in dat geval te spreken van een emfysemateuze pyelitis [1]. 
Figuur 2 a Antegraad pyelogram rechts met een fors gedilateerd kelk-bekkensysteem zonder afloop van contrast richting de ureter. b Retrograad ureteropyelogram rechts met nefrostomie in situ. $\mathrm{Er}$ is sprake van een een normaal anatomisch beloop van de ureter zonder aanwijzingen voor een intrinsieke pyeloureterale junctie stenose
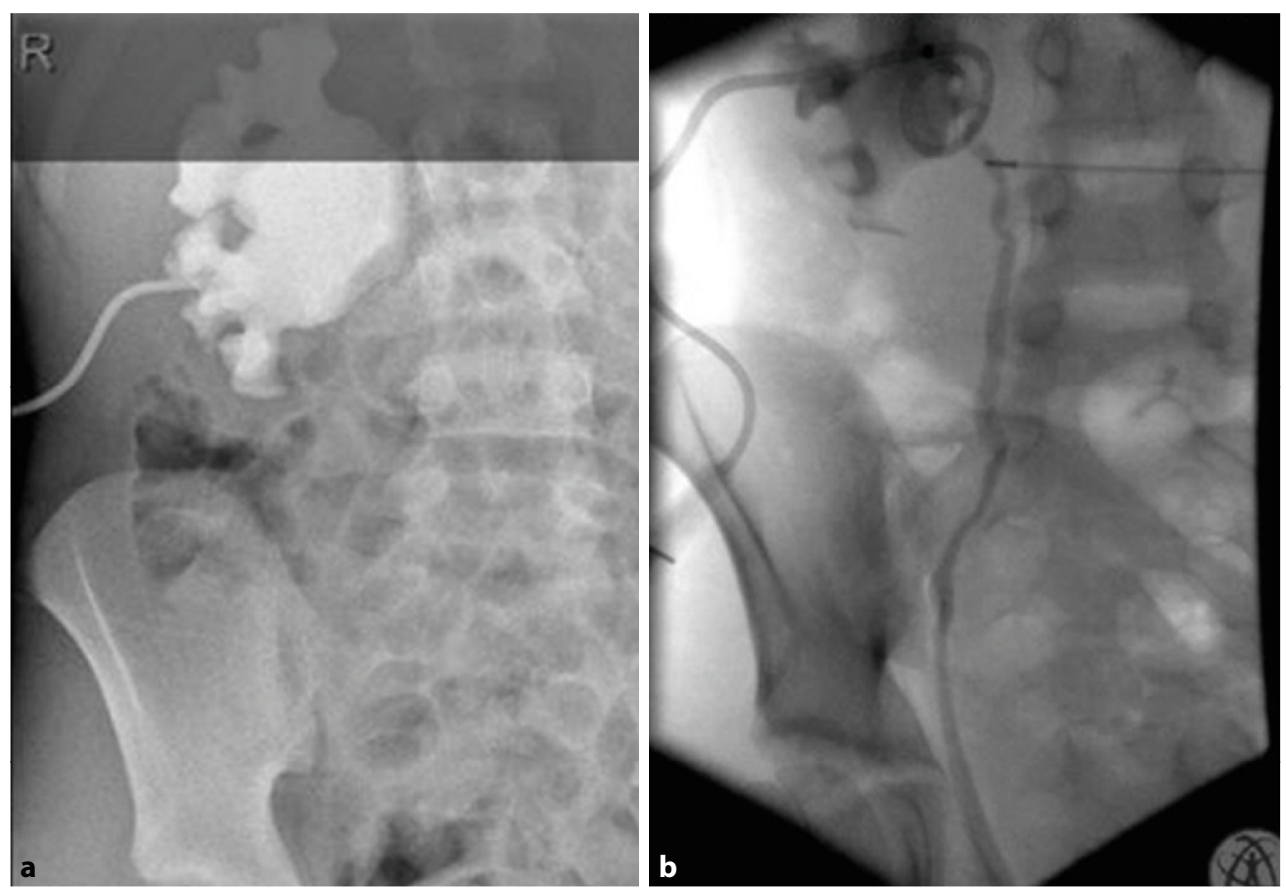

Het eerste geval van EPN bij een volwassen patiënt werd beschreven in 1898 [2]. Sindsdien zijn met de komst van betere beeldvormende technieken meerdere casus gerapporteerd in de nefro-urologische en radiologische literatuur. Het voorkomen van EPN bij kinderen is echter zeer zeldzaam en is voor het eerst door Pode et al. beschreven in 1985 bij een 10-jarige vrouwelijke patiënt [3]. Tot op heden zijn er van EPN bij kinderen acht casus verschenen [3-9].

De pathogenese van EPN is onbekend. Verschillende risicofactoren, zoals de aanwezigheid van gasvormende bacteriën, gestoorde immuniteit, hoge glucoseconcentraties in de weefsels, verstoorde weefselperfusie en urinewegobstructie worden genoemd [10]. De associatie tussen verhoogde glucoseconcentraties en EPN blijkt uit het feit dat in de volwassen populatie $80-90 \%$ van de, vaak vrouwelijke patiënten, lijdt aan diabetes mellitus [11]. Men vermoedt dat de combinatie van hoge glucoseconcentraties met verstoorde weefselperfusie bijdraagt aan het anaeroob metaboliseren van glucose en lactaat door gasvormende micro-organismen, wat leidt tot de productie van vooral koolstofdioxide, waterstof en stikstof. Het kleinere percentage patiënten met EPN zonder diabetes heeft vrijwel altijd een urinewegobstructie van de aangedane zijde [10].

Bij kinderen wordt diabetes niet als risicofactor beschreven. De eerder gepubliceerde casus laten zien dat nefro-urolithiase, gestoorde immuniteit en obstructieve uropathie de voornaamste risicofactoren lijken te zijn [3-9]. In de hier beschreven casus lijkt een PUJ-stenose op basis van overkruisende vaten de oorzakelijke factor. Pathologie van de lage urinewegen werd uitgesloten met een normale uroflowmetrie en urethrocystoscopie. De recent doorgemaakte scrotale cellulitis bij deze specifieke patiënt zou nog kunnen wijzen op een onderliggend afweerprobleem of een diabetes mellitus de novo. Hier werden echter geen aanwijzingen voor gevonden bij het laboratoriumonderzoek.

Escherichia coli is het oorzakelijk uropathogeen in $70 \%$ van alle gevallen van EPN. Andere bekende gasvormende uropathogenen zijn Proteus mirabilis, Klebsiella pneumoniae, groep-D-streptokokken en coagulasenegatieve stafylokokken. Zeldzamere verwekkers zijn Clostridium septicum, Candida albicans, Cryptococcus neoformans en Pneumocystis jerovici [9, 10].

Het klinisch beeld van EPN kan variëren van symptomen van een klassieke pyelonefritis tot symptomen van een ernstige septische shock die leidt tot multiorgaanfalen. In deze casus zijn er symptomen die passen bij een klassieke pyelonefritis zonder dat de patiënt daarbij een acuut zieke indruk maakt. De anamnese van piekende koorts en verwardheid, maar bovenal het afwijkende beeld op echo en CT zijn in dit geval doorslaggevend voor een agressieve aanpak met toediening van een breedspectrumantibioticum en onmiddellijke percutane drainage van de nier. Er is in deze casus specifiek voor percutane drainage gekozen omdat daarmee goede monitoring mogelijk is en na adequate behandeling van de infectie antegrade contraststudies kunnen worden verricht.

Beeldvorming is altijd noodzakelijk om tot de diagnose EPN te komen. Zowel echo als conventioneel röntgenonderzoek van het abdomen kan een EPN doen vermoeden. Typisch voor echografie is de aanwezigheid van reverberatie-artefacten, ook wel dirty shadowing genoemd. Dit wijst, in tegenstelling tot clean shadowing, zoals bij een nefrolithiase, op de aanwezigheid van lucht [12]. Het objectiveren van 


\title{
Hier staat een advertentie.
}

\author{
cC bohn \\ stafleu \\ van loghum
}

Houten 2021 


\title{
Hier staat een advertentie.
}

\author{
cC bohn \\ stafleu \\ van loghum
}

Houten 2021 


\title{
Hier staat een advertentie.
}

\author{
cC bohn \\ stafleu \\ van loghum
}

Houten 2021 


\title{
Hier staat een advertentie.
}

\author{
cC bohn \\ stafleu \\ van loghum
}

Houten 2021 


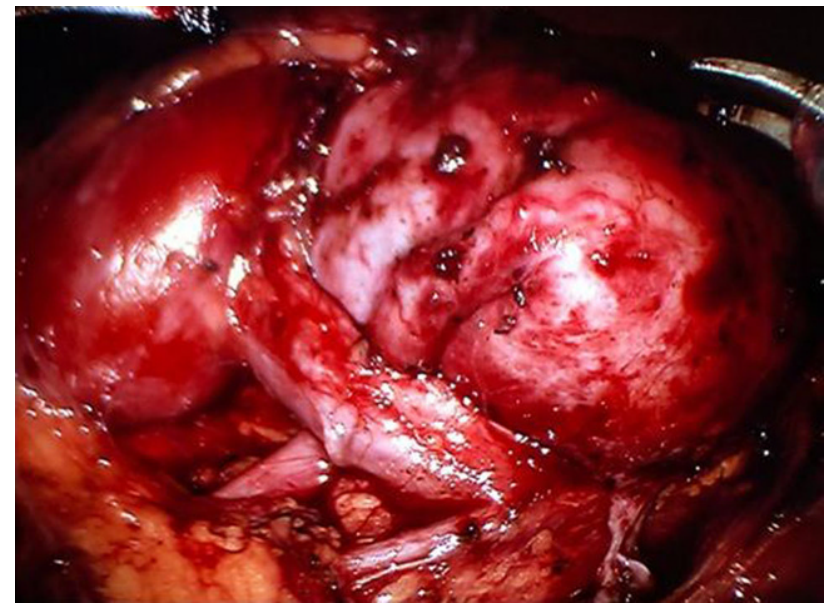

Figuur 3 Peroperatief beeld van de pyelo-ureterale overgang rechts waarbij de ureter wordt afgeknikt door grote overkruisende onderpoolsvaten

lucht in het verzamelsysteem kan soms bemoeilijkt of niet opgemerkt worden door de aanwezigheid van darmgassen in die regio. Een buikoverzichtsfoto kan in ongeveer een derde van de gevallen het beeld van gelokaliseerde gasformatie in de fossa renalis laten zien. In extreme gevallen kan er sprake zijn van een gascollectie binnen de fascie van Gerota met een typische halvemaanvormige configuratie. CT-onderzoek geldt als beste diagnostische modaliteit voor EPN. De CT-scan geeft een indruk van de mate van destructie van het nierparenchym, de hoeveelheid gasformatie, de aanwezigheid van lucht-vloeistofspiegels en focale necrose met of zonder abcesformatie. Bovendien kan CT-onderzoek de onderliggende oorzaak van obstructie van de urinewegen verduidelijken.

Er bestaan drie verschillende op radiologie gebaseerde classificaties van EPN [10, 13, 14]. De eerste classificatie dateert uit 1984, en was van Michaeli et al. Hun classificatie was gebaseerd op conventionele röntgenopnames en intraveneuze pyelografie [13]. Wan et al. kwamen in 1996 met een classificatie op grond van CT-bevindingen bij 38 patiënten. Zij beschreven twee klassen EPN: een klasse 1-EPN, waarbij sprake is van uitgebreide renale destructie met aanwezigheid van gas maar afwezigheid van vochtcollecties en een klasse 2-EPN, waarbij renale of extrarenale vochtcollecties aanwezig zijn, met gasbellen of gasvorming in het pyelocalicieel systeem of de ureter [14]. Bij klasse 1 is de mortaliteitskans significant hoger dan bij klasse 2 (70\% versus $20 \%$ ). De derde en meest gedetailleerde classificatie is ook gebaseerd op CT-bevindingen en is van Huang en Tseng [10]. Zij verrichtten in 2000 een retrospectieve analyse van 48 patiënten met EPN en kwamen tot de volgende classificatie: klasse 1, gasvorming alleen gelokaliseerd in het pyelocalicieel systeem; klasse 2, gasvorming is gelokaliseerd in het nierparenchym; klasse 3A gasvorming uitbreidend tot in de perinefrische ruimte; klasse 3B, gasvorming uitbreidend tot in de pararenale ruimte; klasse 4, EPN bij een mononier of bilaterale manifestatie. De auteurs laten zien dat, hoewel in de kliniek significante verschillen tussen de vier klassen ontbreken, de kans op een slechtere uitkomst toeneemt bij een hogere classificatie. Welke van de hier beschreven drie classificaties men hanteert, hangt af van de voorkeur van de radioloog. Voor de behandelaar is het belangrijk te beseffen dat de classificatie leidend kan zijn in het verdere behandelplan, namelijk conservatief dan wel chirurgisch.

EPN is een potentieel levensbedreigende ziekte met in de volwassen populatie gerapporteerde mortaliteitspercentages tot $70 \%$ [14]. De beperkte literatuur over EPN bij kinderen laat zien dat de mortaliteitskans bij hen een stuk lager lijkt te liggen. Van de tot nu toe acht beschreven casus overleed één patiënt met een klasse 4 EPN [8].

Er bestaat geen consensus over de beste behandeling voor EPN. Waar vroeger nog laagdrempelig besloten werd tot een vroege nefrectomie, ligt tegenwoordig de focus vooral op een adequate resuscitatie van de septische patiënt en spoedige drainage van de urinewegen in geval van obstructie. Zo nodig kan in een later stadium een electieve nefrectomie worden verricht.

Vanwege het ontbreken van consensus stellen Huang en Tseng een behandelprotocol voor aan de hand van hun radiologische classificatie [10]. Voor klasse 1- en 2-EPN adviseren zij een antibiotische behandeling in combinatie met percutane drainage indien er sprake is van een obstructie. Hiermee rapporteren zij een genezingskans van $100 \%$. Dezelfde behandeling, met een succespercentage van $85 \%$, wordt voorgesteld bij klasse 3- en 4-EPN, mits er minder dan twee risicofactoren aanwezig zijn. Deze risicofactoren, die via retrospectieve analyse werden geïdentificeerd, zijn de aanwezigheid van een trombocytopenie, acute nierinsufficiëntie, bewustzijnsstoornis of shock. Bij klasse 3- of 4-EPN en de aanwezigheid van meer dan twee risicofactoren stellen zij de acute nefrectomie voor als behandeling met de beste uitkomst. Belangrijk hierbij te vermelden is dat deze studie is verricht bij volwassen patiënten.

In de pediatrische literatuur is één patiënt met EPN beschreven die werd behandeld met een nefrectomie. Van de overige zeven patiënten die zijn beschreven, ondergingen twee patiënten een antibiotische behandeling in combinatie met percutane drainage. De andere vijf patiënten kregen alleen antibiotische behandeling. Een patiënt overleed ondanks drainage en dialyse. Bij de overige patiënten was de behandeluitkomst goed.

\section{Conclusie}

Een emfysemateuze pyelonefritis bij kinderen is uiterst zeldzaam en is geassocieerd met obstructie van de urinewegen, stenen of een gestoorde afweer. Computertomografisch onderzoek geldt als beste diagnos- 
tische modaliteit. Onmiddellijke en agressieve resuscitatie, het toedienen van antimicrobiële therapie en drainage in geval van obstructie vormen de hoeksteen van de behandeling. In tegenstelling tot de volwassen populatie is de uitkomst bij kinderen met EPN over het algemeen goed.

Open Access This article is distributed under the terms of the Creative Commons Attribution 4.0 International License (http://creativecommons.org/licenses/by/4.0/), which permits unrestricted use, distribution, and reproduction in any medium, provided you give appropriate credit to the original author(s) and the source, provide a link to the Creative Commons license, and indicate if changes were made.

\section{Literatuur}

1. Turman AE, Rutherford C. Emphysematous pyelonephritis with perinephric gas. J Urol. 1971;105:165-70.

2. Kelly HA, MacCullum WG. Pneumaturia. JAMA. 1898; 31:375-81.

3. Pode D, Perlberg S, Fine H. Emphysematous renal and perirenal infection in nondiabetic patient. Urology. 1985; 26:313-5.

4. Fernandes LP, Sajwany MJ, Derweesh A. Emphysematous pyelonephritis and cystitis associated with bilateral pelviureteric junction obstruction: a case report. J Pediatr Surg. 1998;33:739-40.

5. Al-Makadma AS, Al-Akash SI. An unusual case of pyelonephritis in a pediatric renal transplant recipient. Pediatr Transplant. 2005;9:258-60.
6. Siddique K, Seikaly MG. Emphysematous pyelonephritis in an infant. Pediatr Infect Dis J. 2013;32:1157-8.

7. Gross IT, Ford R. Emphysematous pyelonephritis in a child with nephrolithiasis. J Pediatr. 2016;168:250-el.

8. Ambaram PR, Kala UK, Petersen KL. Emphysematous pyelonephritis in children. Pediatr Infect Dis J. 2016;35:1159-61.

9. Girgenti V, Pelizzo G, Amoroso S, et al. Emphysematous pyelonephritis following ureterovesical reimplantation for congenital obstructive megaureter. Pediatric case report and review of the literature. Front Pediatr. 2019;7:2.

10. Huang JJ, Tseng CC. Emphysematous pyelonephritis: clinicoradiological classification, management, prognosis, and pathogenesis. Arch Intern Med. 2000;160:797-805.

11. Pontin AR, Barnes RD, Joffe J, Kahn D. Emphysematous pyelonephritis in diabetic patients. BrJ Urol. 1995;75:71-4.

12. Sommer FG, Taylor KJ. Differentiation of acoustic shadowing due to calculi and gas collections. Radiology. 1980;135:399-403.

13. Michaeli J, Mogle S, Perlberg S, et al. Emphysematous pyelonephritis. JUrol. 1984;131:203-7.

14. Wan YL, Lee TY, Bullard MJ, et al. Acute gas-producing bacterial renal infection: correlation between imaging findings and clinical outcome. Radiology. 1996;198:433-8.

drs. Rens A.L. Jacobs, uroloog, ten tijde van het onderzoek aois urologie

drs. Piet R.H. Callewaert, kinderuroloog 